\title{
EFFICIENCY OF HIGH-STANDARD FARMLAND DEVELOPMENT BASED ON MATTER-ELEMENT EXTENSION AND TOPSIS MODELING
}

\author{
TIAN, J. S. ${ }^{1}-$ JiANG, Z. H. ${ }^{2}-$ GUO, J. C. ${ }^{1 *}-$ LIU, X. ${ }^{1}$ \\ ${ }^{1}$ School of Science, Anhui Agricultural University, Hefei 230036, China \\ ${ }^{2}$ Hefei Pastoral Land Planning and Mapping Company Limited, Hefei 230031, China \\ *Corresponding author \\ e-mail:liuxin@ahau.edu.cn \\ (Received 12 $2^{\text {th }}$ Apr 2019; accepted $11^{\text {th }}$ Jul 2019)
}

\begin{abstract}
To better assess high-standard farmland development projects, this paper built an evaluation system containing three indices: soil efficiency, infrastructure efficiency as well as economic and social efficiency, which were measured after the development of high-standard farmlands. By combining the matter-element extension theory with the TOPSIS model, the authors built a high-standard farmland development evaluation system to assess the soil efficiency, infrastructure efficiency, economic and social efficiency as well as the overall efficiency after completion of a high-standard farmland development project. the authors found the weight of the index for infrastructure efficiency to be 0.46 , with the degree of similarity to the optimal solution reaching 1.0, thus it is rated excellent in terms of its impact on the overall efficiency evaluation; the weight of economic and social efficiency was 0.37 , with its degree of similarity being 0.29 , thus rated good accordingly; while the weight of soil efficiency was 0.17 , with its degree of similarity being 0.00 , thus it had the least impact on overall efficiency. The sequencing result by the TOPSIS model showed that the effective depth of soil had the highest impact on soil efficiency, meanwhile the road access rate influenced infrastructure efficiency the most, and public satisfaction mattered most in terms of economic and social efficiency.
\end{abstract}

Keywords: land development, land engineering, high-standard farmland, evaluation system, efficiency

\section{Introduction}

High-standard farmland development projects normally involve land development, soil improvement, irrigation and water supply, rural road network building, farmland protection and ecological reservation. These projects aim to reduce or remove major restrictions on farmland development and improve their quality. As proposed in the Chinese government document "Opinions on Accelerating Modernization of Agriculture and Building a Moderately Prosperous Society by the Central Government and State Council', the governments at all levels should boost development of highstandard farmlands by increasing investment and integrating financial sponsorship, and governments at all levels should put this endeavour among their top priorities. Thus, development of high-standard farmlands is in fact a land development project in which the scientific evaluation of the project efficiency accounts to be a significant step.

Current Chinese domestic projects (Hwang and Yoon, 1981; Yang et al., 2013; Liu et al., 2012; Zhao and Zhu, 2010; Wu et al., 2008; Li et al., 2010; Xin et al., 2009; Gao et al., 2011) have already studied many topics in this area, including efficiency evaluation of land development projects, evaluation index systems for high-standard farmland development, arable land overall quality evaluation index systems, preliminary location selection of high-standard farmland development, basic farmland demarcation or suitability and timing of high-standard farmland development. For instance, published 
studies have used the TOPSIS (Technique for Order of Preference by Similarity to Ideal Solution) model (Tsaur, 2011; Korkmaz, 2008; Jun et al., 2011; Liu et al., 2006) to analyze priorities in high-standard farmland development, and studied the potential quality of arable land based on grading factors and matter-element modeling (Zhao et al., 2017, 2018). Some of these studies have focused on location selection and division of high-standard farmland by combining the TOPSIS model with the local spatial autocorrelation method (Yang et al., 2018, 2017a, 2017b). Some others have expounded on the feasibility and spatial stability of high-standard farmland development via the TOPSIS model and used the four-quadrant method to analyze the spatial and temporal distribution in high-standard farmland development (Xue et al., 2014). Other studies have explored the time series of high-standard farmland development on the basis of land evaluation and site analysis system (Bian et al., 2016). Nevertheless, current research on the high-standard farmland post-development efficiency have been mainly carried out by way of the entropy weight method, the TOPSIS model or the entropyweight-based matter-element extension model to analyze the efficiency (Xin et al., 2017; Cai and Li, 2014). To enrich the repository of methods for high-standard farmland development evaluation, this research proposed a new evaluation method that combines the matter-element extension model with the TOPSIS model. With the matter element as its basis, the proposed method develops a matter-element model with three post-development indices - soil efficiency, infrastructure efficiency and economic and social efficiency - to evaluate farmland development efficiency through the analysis of the respective weight of the indices in the correlation function. The weights resulting from the function are then introduced into the TOPSIS model to calculate the degree of similarity and evaluate the soil efficiency, infrastructure efficiency, economic and social efficiency as well as the overall efficiency. The result of the weight analysis by way of the correlation function is shown to be in agreement with the result of the efficiencybased similarity analysis.

\section{Materials and methods}

\section{Research area description}

This research takes the high-standard farmland development project of Shangwei Village in Shannan Town, Feixi County of Hefei in Anhui province of China as the research target to evaluate the post-development efficiency. The study area is situated at about $116^{\circ} 45^{\prime}$ to $116^{\circ} 48^{\prime}$ east longitude and $31^{\circ} 40^{\prime}$ to $31^{\circ} 42^{\prime}$ north latitude (Fig. 1). Located in the northwest part of Shannan Town, Shangwei covers an area of $7.9 \mathrm{~km}^{2}$, including $260 \mathrm{hm}^{2}$ of farmlands and $200 \mathrm{hm}^{2}$ of woods. This project area, with its northern part higher than its southern part, mainly consists of hills and is divided into two sections - one in the east and the other in the west - with the County Road No. 042 as the line of demarcation. Subject to the tropical monsoon climate, the area has an average annual temperature that falls between 15 and $16{ }^{\circ} \mathrm{C}$ and an average annual precipitation between 900 and 1000. The whole development project lasted from the end of February 2017 to the beginning of August 2017. Given the actual conditions of the project area, three sampling sites were selected for soil efficiency inside a key development region, where farmlands abound.

Research data presented in this study was collected from diverse sources, including the database for land utilization of Feixi, Heifei, in 2013, the land use map of Feixi prepared in September 2016, the (updated) land use database of Feixi, Heifei, in 2016 
and the overall land use planning map (2006-2020). Other research materials are also referred to, such as the surveyed landform map of the project area in 2016, the planning report for the high-standard farmland development project in 2016, the project completion landform map, the result of a questionnaire survey carried out in October 2017 and sampling research data obtained in October 2017. In the questionnaire survey, 95 questionnaires were collected from the total of 100 distributed. According to China's high-standard farmland construction standards and evaluation criteria for high-standard farmland construction, the target groups of the questionnaire survey were mainly local farmers, managers and acceptance experts. Among the participants, the ages were mainly between 30 and 60 years old, the education experience of senior high school and college were the main one.

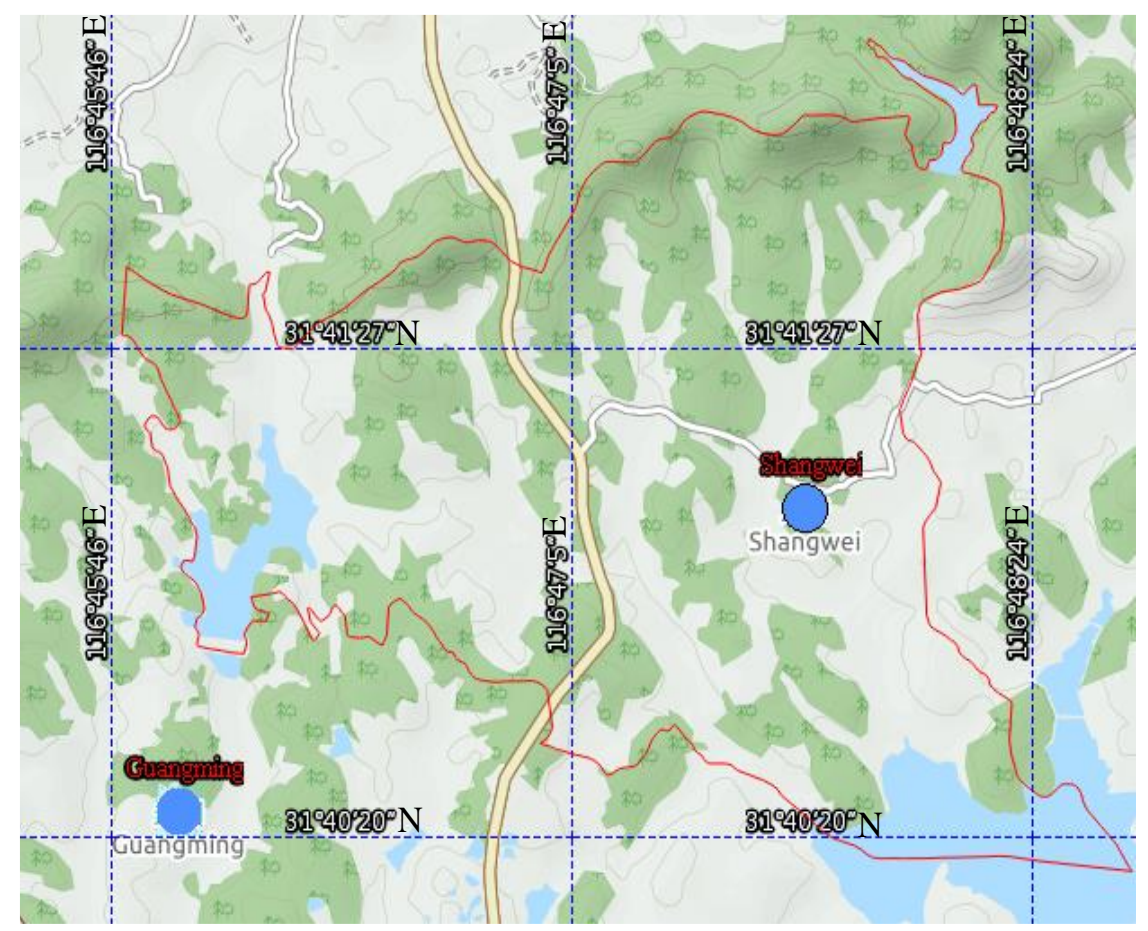

Figure 1. Location map of research area (Feixi County of Hefei in China)

\section{Research methodology}

The core objective of high-standard farmland development is to maximize economic and social efficiency while ensuring ecological conservation. Extenics is a subject that studies the possibility of extension of matters and explores the law and methods for innovation of the extensibility of matters through formalized models to address problems. There are diverse indicators for evaluation of high-standard farmland efficiency and results from single-index evaluation methods are usually incompatible with each other, therefore, the Extenics theory, which is applicable to such research situations, is applicable to this study. The TOPSIS method works out the degree of similarity between the calculated results and the optimal solution to evaluate the results' quality. The TOPSIS method is based on the Euclidean distance calculated between the positive ideal solution (PIS) and the negative ideal solution (NIS). As presented above, this project presents an evaluation system with three indices (soil efficiency, 
infrastructure efficiency and economic and social efficiency) according to the highstandard farmland development criteria (Criterion of High Standard Farmland, 2012), establishes a weight model of correlation function index based on matter elements and analyzes the development results. The weights obtained via the correlation function are introduced into the TOPSIS model, which is then optimized to work out the degree of similarity of each index to the ideal solution. In this way, an evaluation can be made on the soil efficiency, infrastructure efficiency, economic and social efficiency as well as the overall efficiency of the high-standard farmland development project.

\section{Evaluation index system}

Based on existing studies and the actual conditions of the project area, the model presents an evaluation system of indices, assuming that the indices are representative, comparable, operable and quantitative. The efficiency of high-standard farmland development is taken as the evaluation target, with three indices - soil efficiency, infrastructure efficiency, economic and social efficiency - as the evaluation criteria. Each evaluation index includes multiple criteria with deciding factors, as shown for the index system in Table 1. According to domestic research publications, the degree of similarity is divided into four levels to make a qualitative evaluation. The criteria are as follows: when the degree of similarity stands between 0.80 and 1.00 , the efficiency is rated "excellent"; when the number falls between 0.60 and 0.80 , the efficiency is rated "good"; the efficiency is rated "moderate" when the number is between 0.30 and 0.60 ; while it is rated "poor" if the number stays between 0.00 and 0.30 .

Table 1. Efficiency evaluation index system

\begin{tabular}{|c|c|c|c|c|c|}
\hline Target & $\begin{array}{l}\text { Criterion and } \\
\text { code }\end{array}$ & Index (deciding factors) and code & Index type & Mean & $\begin{array}{c}\text { Suitable } \\
\text { value }\end{array}$ \\
\hline \multirow{10}{*}{ 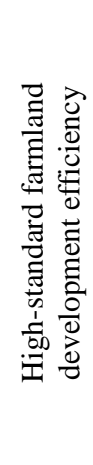 } & \multirow{3}{*}{$\begin{array}{l}\text { Soil efficiency } \\
\qquad\left(O_{11}\right)\end{array}$} & Effective depth of soil $(\mathrm{cm}) c_{1}$ & Positive & 60.0 & 100 \\
\hline & & Organic content of soil $(\mathrm{g} / \mathrm{kg}) c_{2}$ & Positive & 11.6 & 20 \\
\hline & & $\mathrm{pH}$ scale $c_{3}$ & Suitable & 6.8 & $6.0-7.9$ \\
\hline & \multirow{4}{*}{$\begin{array}{l}\text { Infrastructure } \\
\text { efficiency }\left(O_{21}\right)\end{array}$} & Agricultural mechanization level (\%) $c_{4}$ & Positive & 75.0 & 100 \\
\hline & & Irrigation water utilization coefficient $c_{5}$ & Positive & 0.6 & 1.0 \\
\hline & & Rate of guaranteed irrigation $(\%) c_{6}$ & Positive & 85.0 & 100 \\
\hline & & Road access rate $(\%) c_{7}$ & Positive & 90.0 & 100 \\
\hline & \multirow{3}{*}{$\begin{array}{l}\text { Economic and } \\
\text { social efficiency } \\
\left(O_{31}\right)\end{array}$} & Agricultural production cost $\left(10000 \mathrm{rmb} / \mathrm{hm}^{2}\right) c 8$ & Negative & 1.6 & 0 \\
\hline & & Static return on investment $(\%) c_{9}$ & Positive & 7.1 & 100 \\
\hline & & Degree of public satisfaction $(\%) c_{10}$ & Positive & 93.0 & 100 \\
\hline
\end{tabular}

(1) The indices and suitable values in the table above are identified by referring to relevant regulations for highstandard farmland development (Farmland Construction, 2016; Regulation for Gradation on Agriculture Land Quality, 2012; Cultivated Land Quality Grade, 2016) and related research publications. (2) The average score of soil efficiency is obtained from sampling of the sites, from scores of infrastructure efficiency from scoring results by experts, and from scores of the economic and social efficiency from questionnaire surveys. (3) Agricultural production cost and static return on investment refer to economic efficiency; degree of public satisfaction represents social efficiency

\section{High-standard farmland development efficiency evaluation}

The matter-element extension model and TOPSIS model are combined to evaluate the soil efficiency, infrastructure efficiency, economic and social efficiency as well as the overall efficiency of the high-standard farmland development project. 


\section{Matter-element model building}

According to previous published models (Zhao and Su, 2010; Cai et al., 2008; Yang and Cai, 2008), $O_{m j}$ is set with $j$ levels of evaluation; $c_{i}$ is the evaluation index for standard levels; $V_{m j i}$ is the range of classical field defined by the respective levels of indices; $a_{m j i}$ and $b_{m j i}$ are the upper limit and lower limit of the classical field, respectively; $P$ is the evaluation standard; $x_{p i}$ is the range of the segment field of $P$ in terms of each evaluation index of $c_{i} ; a_{p i}$ and $b_{p i}$ are the upper limit and lower limit of the segment field, respectively; $Q$ represents the matter element to be evaluated (development efficiency) and $x$ is the efficiency value of $Q$ in terms of the evaluation index $c_{i}$. The relation between $x_{p i}$, the segment field value, and $v_{m j i}$, the classical field value, is $v_{m j i} \subset x_{p i}$. The classical matter element model, the segment field matter element model and the to-be-evaluated matter element model that can be built are as follows: $M_{m j}=\left(O_{m j}, c_{i}, v_{m j i}\right), M_{p}=\left(P, c_{i}, x_{p i}\right), M_{q}=\left(Q, c_{i}, x_{i}\right)$.

\section{Weight model building}

In the evaluation of efficiency (Zhao and Su, 2010; Cai et al., 2008; Yang and Cai, 2008), the weighing method can help measure differences among indices, but in most cases, the scoring method, which involves subjective judgements, dominates and undermines the objectivity of the result. By introducing the average score of each index into the classical field and segment field of the matter-element extension model, our model calculates the weight of each index through the correlation function to decide whether the index meets the standard, so that the result can steer clear of subjective errors and $w_{i}$, the normalized weight of $c_{i}$, can be calculated. When $x_{i} \in x_{p i}$ (segment field), the classical field is $v_{m j i}=\left(a_{m j i}, b_{m j i}\right)$, with $i=1,2, \cdots n$ (evaluation index) and $j=1,2, \cdots m$ (evaluation standard level), then the correlation function between the evaluation value and the classical field presents as:

$$
K_{j i}\left(x_{i}, v_{m j i}\right)=\left\{\begin{array}{l}
\frac{2\left(x_{i}-a_{m j i}\right)}{b_{m j i}-a_{m j i}}, \text { when } x_{i} \leq \frac{a_{m j i}+b_{m j i}}{2} \\
\frac{2\left(b_{m j i}-x_{i}\right)}{b_{m j i}-a_{m j i}}, \text { when } x_{i}>\frac{a_{m j i}+b_{m j i}}{2}
\end{array}\right.
$$

In Equation 1, $K_{j i}\left(x_{i}, V_{m j i}\right)$ refers to the simple correlation value between the actual efficiency values and corresponding standard values of evaluation indices; other symbols follow the same pattern in meaning. $j$ stands for the level of evaluation standard. The larger $j$ is, the larger the represented index's influence on the criteria is. The correlative weight calculation model then presents as:

$$
q_{i}=\left\{\begin{array}{l}
j \times\left(1+\max \left(K_{j i}\left(x_{i}, v_{m j i}\right)\right)\right), \text { when } \max \left(K_{j i}\left(x_{i}, v_{m j i}\right)\right) \geq-\frac{1}{2} \\
0.5 \times j, \text { when } \max \left(K_{j i}\left(x_{i}, v_{m j i}\right)\right)<-\frac{1}{2}
\end{array}\right.
$$


In Equation 2, $j$ stands for the highest level of evaluation. On the contrary, the smaller $j$ is, the smaller the corresponding index's influence on the criteria is. In this case, the correlation weight calculation model is:

$$
q_{i}=\left\{\begin{array}{l}
(m-j+1) \times\left(1+\max \left(K_{j i}\left(x_{i}, v_{m j i}\right)\right)\right), \text { when } \max \left(K_{j i}\left(x_{i}, v_{m j i}\right)\right) \geq-\frac{1}{2} \\
0.5 \times(m-j+1), \text { when } \max \left(K_{j i}\left(x_{i}, v_{m j i}\right)\right)<-\frac{1}{2}
\end{array}\right.
$$

In Equation 3, $j$ stands for the lowest level of evaluation and $m$ is the number of evaluation levels.

\section{TOPSIS model}

TOPSIS is a multi-criteria analysis method, which was originally proposed by Hwang and Yoon in 1981 to compare different solutions, and it is also an integrated evaluation method for multi-objective and decision-making solutions. It can not only make the best of the original data and reflect the gap between different decision-making solutions, but also describe the general condition of the objectives or specific targets in an authentic, direct and reliable way, therefore it is widely applicable. The authors assumed that there are a total of $m$ objectives, each of which has $n$ attributes, and the initial value of the attribute $j^{\text {th }}$ of the objective $i^{t h}$ is $x_{i j}$, the initial evaluation matrix $V$ is then formed. As the dimensions of indices vary, the initial matrix is normalized into the normalized matrix $V^{\prime}$. By combining the weight matrix $W$ obtained from the correlation function model with the normalized initial evaluation matrix $V^{\prime}$, the weighted evaluation matrix $Z$ is obtained.

(1) We first calculated the positive ideal solution (PIS) and negative ideal solution (NIS) of the evaluated objective through the weighted judgement matrix, then worked out the Euclidean distance that each objective has from PIS and NIS, and last the following model is built:

$$
\begin{aligned}
& \text { Euclidean distance from PIS: } S_{i}^{+}=\sqrt{\sum_{j=1}^{m}\left(f_{i j}-f_{j}^{+}\right)^{2}}, j=1,2, \ldots, n \\
& \text { Euclidean distance from NIS: } S_{i}^{-}=\sqrt{\sum_{j=1}^{m}\left(f_{i j}-f_{j}^{-}\right)^{2}}, j=1,2, \ldots, n
\end{aligned}
$$

(2) Next, the authors calculated $C_{i}$, the degree of similarity of each objective to the optimal solution (or optimal value):

$$
C_{i}=S_{i}^{-} /\left(S_{i}^{+}+S_{i}^{-}\right), \quad i=1,2, \ldots, m
$$

According to $C_{i}$, the scale of the similarity, the objectives can then be sequenced to create the basis for decision-making. In Equation 6, the larger $C_{i}$ is, the closer the efficiency of the item $i^{\text {th }}$ is to the optimal value. The values for the degree of similarity fall within the range from 0.00 to 1.00 , and the closer the value is to 1.00 , the better the 
corresponding index's efficiency is; on the contrary, similarity closer to 0.00 means poorer efficiency.

\section{Data analysis process}

\section{Data processing}

\section{Range identification of classical field and segment field}

The correlation function in the matter-element extension model plays a pivotal role in determining the weights of indices, and it is related to the classical field and segment field in the model. The conventional methods to identify the range include work experience-based identification by experts, criteria-based identification, sampling databased identification and others. On the basis of previous reports describing criteria for high-standard farmland development, the research presented here, by referring to data collected from sampling sites of completed projects, statistics from questionnaire surveys and consultation with experts, identifies the ranges of the classical field and the segment field at four evaluation levels for the corresponding indices, as shown in Table 2.

Table 2. Range of the classical fields and the segment fields of evaluation indices

\begin{tabular}{c|c|c|c|c|c}
\hline \multirow{2}{*}{ Index code } & \multicolumn{4}{|c|}{ Classical field range } & Segment field \\
\cline { 2 - 5 } & Poor & Moderate & Good & Excellent & range \\
\hline$c_{1}$ & {$[30,50)$} & {$[50,60)$} & {$[60,70)$} & {$[70,100]$} & {$[30,100]$} \\
$c_{2}$ & {$[0,5)$} & {$[5,10)$} & {$[10,20)$} & $\geq 20$ & {$[0,20]$} \\
$c_{3}$ & {$[4.5,5.5]$} & $(5.5,6.0]$ & $(6.0,6.5]$ & $(6.5,7.9]$ & {$[4.5,7.9]$} \\
$c_{4}$ & {$[0,50)$} & {$[50,60)$} & {$[60,70]$} & {$[70,100]$} & {$[0,100]$} \\
$c_{5}$ & {$[0.1,0.5)$} & {$[0.5,0.55)$} & {$[0.55,0.6)$} & {$[0.6,1.0]$} & {$[0.1,1.0]$} \\
$c_{6}$ & {$[10,50)$} & {$[50,60)$} & {$[60,70]$} & {$[70,100]$} & {$[10,100]$} \\
$c_{7}$ & {$[30,50)$} & $(50,60)$ & $(60,80)$ & $(80,100)$ & {$[30,100]$} \\
$c_{8}$ & $\geq 2.0$ & $(2.0,1.5)$ & $(1.5,1.0)$ & $<1.0$ & {$[0,2]$} \\
$c_{9}$ & {$[0,5]$} & {$[5,8]$} & {$[8,10]$} & $>10$ & {$[0,10]$} \\
$c_{10}$ & {$[0,50]$} & {$[50,60]$} & {$[60,75]$} & {$[75,100]$} & {$[0,100]$} \\
\hline
\end{tabular}

\section{Index weight in the TOPSIS model}

The standard level that an index's evaluation value belongs to is represented by $j$. A larger value of $j$ means larger influence of the index on the criteria, hence deserving a larger scale of weight; on the contrary, a smaller $j$ means less influence of the corresponding index on the criteria, hence deserving a smaller weight. The results are shown in Table 3.

Processing of data on soil efficiency, infrastructure efficiency and economic and social efficiency through the TOPSIS model

The main components of high-standard farmland development evaluation criteria include: construction task evaluation, construction quality evaluation, construction effectiveness evaluation, construction management evaluation, social impact evaluation 
and comprehensive evaluation (Assessment Standard of Well-Facilitated Farmland Construction, 2016; Criterion of High Standard Farmland, 2012). The high-standard farmland development project, in planning and location selection, aims to improve the infrastructure, increase the level of agricultural automation and achieve agricultural mass production in the selected area. The infrastructure in the selected area is largely poor in quality and suffers from damages, which undermines the land productivity and the level of agricultural mechanization. Besides, irrigation-caused pit ponds and collapses of irrigation canals are rife among alluvial farm fields, casting a blight on agricultural irrigation. When the project is completed, project-acceptance experts select three sampling sites in the project area to assess the soil efficiency. According to the principles of TOPSIS modeling and given the inconsistent quantitative units of indices, the original evaluation matrix is normalized to produce and sequence the degree of similarity of the soil efficiency, infrastructure efficiency as well as economic and social efficiency, as shown in Table 4. The statistics for infrastructure efficiency are taken from scores by project-acceptance experts and those for economic and social efficiency are from questionnaire surveys.

Table 3. Index weight

\begin{tabular}{c|c|c|c|c}
\hline \multirow{2}{*}{ Index code } & \multicolumn{4}{|c}{ Weight } \\
\cline { 2 - 5 } & $\begin{array}{c}\text { Index } \\
\text { correlated }\end{array}$ & $\begin{array}{c}\text { Index } \\
\text { normalized }\end{array}$ & $\begin{array}{c}\text { Criterion } \\
\text { correlated }\end{array}$ & $\begin{array}{c}\text { Criterion } \\
\text { normalized }\end{array}$ \\
\hline$c_{1}$ & 12.60 & 0.68 & & \\
$c_{2}$ & 3.20 & 0.17 & 18.60 & 0.17 \\
$c_{3}$ & 2.80 & 0.15 & & \\
$c_{4}$ & 11.00 & 0.21 & & \\
$c_{5}$ & 9.00 & 0.18 & 51.00 & 0.46 \\
$c_{6}$ & 13.00 & 0.26 & & \\
$c_{7}$ & 18.00 & 0.35 & & \\
$c_{8}$ & 3.20 & 0.08 & & \\
$c_{9}$ & 16.80 & 0.40 & 41.60 & \\
$c_{10}$ & 21.60 & 0.52 & & \\
\hline
\end{tabular}

Table 4. Efficiency index evaluation matrix and similarity degree

\begin{tabular}{c|c|c|c|c|c|c|c}
\hline Efficiency & Index & \multicolumn{3}{|c|}{ Normalized evaluation } & Similarity & Ranking \\
\hline \multirow{3}{*}{ Soil efficiency } & $c_{1}$ & 0.9768 & 0.9762 & 0.9745 & & 1.00 & 1 \\
& $c_{2}$ & 0.1841 & 0.1878 & 0.1936 & & 0.09 & 2 \\
& $c_{3}$ & 0.1098 & 0.1085 & 0.1132 & & 0.00 & 3 \\
& $c_{4}$ & 0.4953 & 0.5009 & 0.4937 & 0.4785 & 0.77 & 3 \\
Infrastructure & $c_{5}$ & 0.0034 & 0.0051 & 0.0042 & 0.0042 & 0.00 & 4 \\
efficiency & $c_{6}$ & 0.5979 & 0.5956 & 0.5937 & 0.6035 & 0.94 & 2 \\
& $c_{7}$ & 0.6302 & 0.6279 & 0.6354 & 0.6378 & 1.00 & 1 \\
Economic and social & $c_{8}$ & 0.0164 & 0.0176 & 0.0173 & 0.0164 & 0.00 & 3 \\
efficiency & $c_{9}$ & 0.0761 & 0.0774 & 0.0748 & 0.0761 & 0.06 & 2 \\
& $c_{10}$ & 0.9970 & 0.9968 & 0.9970 & 0.9970 & 1.00 & 1 \\
\hline
\end{tabular}




\section{Processing of data on overall efficiency through the TOPSIS model}

Based on data from Tables 1-4, our model makes use of the TOPSIS model to calculate and sequence the degree of similarity of three decision-making factors for overall efficiency, as shown in Table 5.

Table 5. Overall efficiency evaluation matrix and similarity degree

\begin{tabular}{c|c|c|c|c|c|c|c}
\hline \multirow{2}{*}{ Criterion } & \multicolumn{3}{|c|}{$\begin{array}{c}\text { Normalized judgement } \\
\text { matrix }\end{array}$} & $\begin{array}{c}\text { Distance } \\
\text { from PIS }\end{array}$ & $\begin{array}{c}\text { Distance } \\
\text { from NIS }\end{array}$ & Similarity & Ranking \\
\hline$o_{11}$ & 1.2722 & 1.2753 & 1.2769 & 0.1621 & 0.0001 & 0.00 & 3 \\
$o_{21}$ & 1.7267 & 1.7280 & 1.7259 & 0.0001 & 0.1621 & 1.00 & 1 \\
$o_{31}$ & 1.0873 & 1.0932 & 1.0900 & 0.1152 & 0.0469 & 0.29 & 2 \\
\hline
\end{tabular}

\section{Results analysis}

In light of the leveling criteria of efficiency indices and based on the results of Tables 3-5, we analyze our results in two different ways: the weights of indices and the TOPSIS modeling results.

\section{Soil efficiency analysis}

(1) Analysis of index weight based on the correlation function. The results of normalized weight analysis on the criterion level after completion of the high-standard farmland development project follow the order: effective depth of soil (0.68) > Organic content of soil $(0.17)>\mathrm{pH}$ scale $(0.15)$. This means that, among the factors that influence the soil efficiency, the effective depth of soil accounts for the largest indicator, hence it has the largest weight, followed by the organic content of soil and then by the $\mathrm{pH}$ scale. According to Jenks natural breaks method, indicators having a weight equaled or above 0.3 are important indicators, those within the range $[0.1,0.3$ ) are secondary indicators and those smaller than 0.1 are boundary indicators. Therefore, among all the indicators for soil efficiency, the effective depth of soil is an important indicator, the organic content of soil a secondary indicator and the $\mathrm{pH}$ scale a boundary indicator.

(2) Analysis of the TOPSIS modeling results. The indicator effective depth of soil has the longest distance from the NIS, with a degree of similarity of 0.6177 , while its distance from the optimal solution approaches 1.00 , hence it is rated excellent in efficiency, which means that this indicator has the largest influence on soil efficiency; the distance of the indicator organic content of soil from PIS is 0.5603, and its distance from NIS is 0.09 , so the indicator is rated poor in efficiency and plays a secondary role; the distance of the indicator $\mathrm{pH}$ scale from PIS is 0.6177 , and its distance from the optimal solution is 0.00 , so it is rated poor in efficiency and has the least influence. These indicators are ranked in the model in the following order: effective depth of soil, organic content of soil and $\mathrm{pH}$ scale.

\section{Infrastructure efficiency analysis}

(1) Analysis of the index weight based on the correlation function. The results of normalized weight analysis of infrastructure efficiency follow the order: road access rate $(0.35)>$ rate of guaranteed irrigation $(0.26)>$ agricultural mechanization level 
$(0.21)>$ irrigation water utilization rate (0.18). This means that, among the indicators for infrastructure efficiency, the road access rate plays the most important part, followed by the rate of guaranteed irrigation and then the agricultural mechanization level, with the irrigation water utilization rate having the least impact. According to Jenks natural breaks method, among the decision-making factors for infrastructure efficiency, road access rate is an important indicator, the rate of guaranteed irrigation, agricultural mechanization level and irrigation water utilization rate are secondary indicators, and there are no boundary indicators.

(2) Analysis of the TOPSIS modeling results. The indicator of road access rate has the longest distance from NIS, with a degree of similarity of 0.3273 , and its distance from the optimal solution is 1.00 , so it is rated excellent and has the largest influence on infrastructure efficiency. The distance of the indicator rate of guaranteed irrigation from NIS is 0.3081 , and its degree of similarity to the optimal solution is 0.94 , so it is rated excellent and plays a secondary role in infrastructure efficiency. The distance of agricultural mechanization level from PIS is 0.0741 , and its degree of similarity to the optimal solution is 0.77 , so the indicator is rated good and plays a relatively important role in infrastructure efficiency. The irrigation water utilization rate is most distant from the PIS, with a distance of 0.3273 , and its degree of similarity to the optimal solution is 0.00 , so it is rated poor in efficiency level and does not have much impact on infrastructure efficiency. These indicators are ranked in the model in the following order: road access rate, rate of guaranteed irrigation, agricultural mechanization level and irrigation water utilization rate.

\section{Economic and social efficiency analysis}

(1) Analysis of index weight based on the correlation function. The results of normalized weight analysis of economic and social efficiency follow the order: rate of public satisfaction $(0.52)>$ static return on investment $(0.40)>$ agricultural production cost (0.08). It means that among the indicators affecting economic and social efficiency, the rate of public satisfaction weighs the highest, followed by static return on investment and then by the agricultural productivity cost. According to Jenks natural breaks method, among the decision-making factors for economic and social efficiency, the indicators of rates of public satisfaction and static return on investment are important indicators, and the agricultural production cost is a boundary indicator, as the agricultural production cost is correlated with many unpredictable factors such as the environment and weather (unfavorable weather will increase the cost). The highstandard farmland development project improves the roads, achieves a general mechanization of agricultural production and reduces the workload and extra expenditures. With the cost of fertilization basically unchanged, the agricultural production cost is reduced, moreover, the static return on investment and the rate of public satisfaction would be both increased.

(2) Analysis based on the TOPSIS modeling results. The rate of public satisfaction is the most distant from the NIS, with a distance of 0.6477 , and its degree of similarity to the optimal solution is 1.00 , so this indicator is rated excellent in efficiency level and has the largest impact on economic and social efficiency; the indicator of static return on investment has a distance of 0.6091 from the NIS, and its degree of similarity to the optimal solution is 0.06 , so it is rated poor in efficiency level and plays a secondary role in economic and social efficiency; the agricultural production cost has the longest distance from the PIS, 0.6477 , and its degree of similarity to the optimal solution is 
0.00 , so it has the least impact on economic and social efficiency. These indicators are ranked in the model in the following order: rate of public satisfaction, static return on investment and agricultural production cost.

\section{Overall efficiency analysis}

(1) Analysis based on index weight and the correlation function. The normalized weight analysis in terms of the criteria in the high-standard farmland development project is presented in the following expression: infrastructure efficiency $(0.46)>$ economic and social efficiency $(0.37)>$ soil efficiency $(0.17)$. This order indicates that, among the indices that influence the project's overall efficiency, infrastructure efficiency has the largest weight, followed by economic and social efficiency, while soil efficiency has the least impact. According to Jenks natural breaks method, the infrastructure efficiency and the economic and social efficiency are thus rated as important indicators, while soil efficiency is a secondary indicator. Infrastructure efficiency consists of one important indicator and three secondary indicators, without boundary indicators; economic and social efficiency includes two important indicators and one boundary indicator; soil efficiency involves one important indicator, one secondary and one boundary. Therefore, it can be concluded that the infrastructure efficiency is positively correlated with the overall efficiency, while soil efficiency, with a lower value, is in negative correlation with the overall efficiency.

(2) Analysis of the TOPSIS modeling results. The infrastructure efficiency is the most distant from NIS, with a distance at 0.1621 , and its degree of similarity to the optimal solution is 1.00 , so its efficiency level is rated excellent; in the case of economic and social efficiency, its distance from NIS is $0.0469,0.1152$ from PIS and its degree of similarity to the optimal solution is 0.29 , so it is rated as poor in the efficiency level and plays a secondary role in the overall efficiency; the degree of similarity of soil efficiency to the optimal solution is 0.00 , so soil efficiency is rated poor in the efficiency level and has the least impact on overall efficiency.

To summarize, the index weight analysis results based on correlation functions and those of the TOPSIS modeling are consistent. According to the mean score and suitability score of the project shown in Table 1, the key to the overall efficiency of high-standard farmland development is to improve infrastructure efficiency.

\section{Conclusions}

(1) The advantage of matter-element modeling is that it extends the actual evaluation indices which are not within the range of the standard values towards the standard values, with the correlation function identifying the positive field, negative field and zero field. The range of the correlation function is $(-\infty,+\infty)$, so it reflects the status of an object in a more accurate way and thus facilitates quantitative evaluation. These advantages are what the traditional fuzzy comprehensive evaluation method and analytic hierarchy process cannot provide. Meanwhile, by sequencing the weights of indices and leveling their respective impacts, the model found that infrastructure efficiency and economic and social efficiency are important indicators in the overall efficiency evaluation, while soil efficiency is a secondary indicator.

(2) The overall efficiency of the high-standard farmland development project is reflected by three indices -soil efficiency, infrastructure efficiency and economic and social efficiency. It is found that infrastructure efficiency is the most distant from the 
NIS, with a distance of 0.1621 , and its degree of similarity to the optimal solution is 1.00 , so it is rated excellent in efficiency level while the soil efficiency has the least impact on the overall efficiency, with its degree of similarity to the optimal solution standing at 0.00 .

\section{Discussion}

(1) The presented research combines matter-element extension modeling with TOPSIS modeling for high-standard farmland development efficiency evaluation. Compared with previous reported methods (Xue et al., 2014; Bian et al., 2016; Xin et al., 2017; Cai and Li, 2014; Tsaur, 2011; Korkmaz, 2008; Jun et al., 2011; Liu et al., 2006), the method used in this work has several advantages. Specifically, by constructing a matter-element model of classical and segment fields, it utilized the extensibility of matter elements to identify the evaluation objectives accurately and comprehensively; and by analyzing the correlation degree among factors in the correlation function, the model calculated the weight of each index, normalized the weight matrix and improved the weight measurement method to avoid the influence of subjective factors on the evaluation result.

(2) It is of great importance to select indices scientifically in evaluating efficiency of high-standard farmland development. The evaluation index system in this paper was built based on analysis of previous published studies, the particular situation of the project area and in consultation with project-acceptance experts. Ecological factors were not taken into account and only one indicator, public satisfaction, was included in the index of social efficiency. In this study, the authors did not compare the results with other results from different research methods, due to limitations on the overall length of the manuscript. In subsequent studies, the authors expect to improve the presented model to increase the accuracy of the research results.

Acknowledgements. These researches were financially supported by Quality Engineering (Teaching Research Project) of Anhui Agricultural University (Grant No. 2018aujyxm047) and National Natural Science Foundation of China (Grant No. 41504031).

\section{REFERENCES}

[1] Assessment Standard of Well-Facilitated Farmland Construction (2016): 2016GB/T33130. - General Administration of Quality Supervision Inspection and Quarantine of the People's Republic of China, Beijing.

[2] Bian, Z. X., Yang, Z. J., Qian, F. K. (2016): Study on time sequence of high-standard prime farmland based on LESA. - Journal of Natural Resources 31(3): 436-446.

[3] Cai, J., Li, S. P. (2014): Social effects evaluation of high-standard primary farmland construction project based on entropy-weighted method and extension model. - China Land Sciences 28(10): 40-47.

[4] Cai, W., Yang, C. Y., Chen, W. W. (2008): Extension Set and Extension Data Mining. The Science Publishing Company, Beijing.

[5] Criterion of High Standard Farmland (2012): 2012-NY/T 2148. - Ministry of Agriculture and Rural Affairs of the People's Republic of China, Beijing.

[6] Cultivated Land Quality Grade (2016): 2016-GB/T33469. - General Administration of Quality Supervision Inspection and Quarantine of the People's Republic of China, Beijing. 
[7] Gao, M. X., Zhang, Q., Zhao, G. X. (2011): Evaluation methods and application of land consolidation. - Transactions of the Chinese Society of Agricultural Engineering 7(10): 300-307.

[8] Hwang, C. L., Yoon, K. (1981): Methods for Multiple Attribute Decision Making. Springer, Berlin.

[9] Jun, K. S., Chung, E. S., Sung, J. Y., et al. (2011): Development of spatial water resources vulnerability index considering climate change impacts. - Science of the Total Environment 409(24): 5228-5242.

[10] Korkmaz, M. (2008): Analysis of economic efficiency at forest enterprises with TOPSIS method. - Optical Engineering 47(5): 525-534.

[11] Li, Z., Wang, J., Bai, Z. K. (2010): Method of comprehensive benefit evaluation of land consolidation based on evaluation model of matter element. - Bulletin of Soil and Water Conservation 30(6): 190-194.

[12] Liu, C., Frazier, P., Kumar, L., et al. (2006): Catchment-wide wetland assessment and prioritization using the multi-criteria decision making method TOPSIS. - Environmental Management 38(2): 316-326.

[13] Liu, L., Yu, L., Li, Z. (2012): Study on evaluation of integrated benefit of land consolidation based on ameliorated Fuzzy AHP. - Research of Soil and Water Conservation 19(3): 204-208.

[14] Regulation for Gradation on Agriculture Land Quality (2012): 2012-GB/T2845. General Administration of Quality Supervision Inspection and Quarantine of the People's Republic of China, Beijing.

[15] Tan, X., Wang, X. R., Tang, H. Z. (2013): Evaluation index system and method on construction condition of county well-facilitated capital farmland: a case study of Mianzhu County. - Southwest China Journal of Agricultural Sciences 26(5): 1977-1983.

[16] Tsaur, R. C. (2011): Decision risk analysis for an interval TOPSIS method. - Applied Mathematics \& Computation 218(8): 4295-4304.

[17] Wu, G. C., Liu, D. Z., Fu, G. H. (2008): Social benefit evaluation of land reconsolidation projects based on entropy-weighted extentic matter- element model. - China Land Science 22(5): 40-46.

[18] Xin, G. X., Yang, Q. Y., Yang, H. J. (2009): Impact assessment of land consolidation post-project. - Transactions of the Chinese Society of Agricultural Engineering 25(11): 312-317.

[19] Xin, G. X., Yang, C. X., Yang, Q. Y. (2017): Post-evaluation of well-facilitated capital farmland construction based on entropy weight method and improved TOPSIS model. Transactions of the Chinese Society of Agricultural Engineering 33(1): 238-249.

[20] Xue, J., Han, J., Zhang, F. R. (2014): Development of evaluation model and determination of its construction sequence for well-facilitated capital farmland. Transactions of the Chinese Society of Agricultural Engineering 30(5): 193-203.

[21] Yang, C. Y., Cai, W. (2008): Extension Engineering. - The Science Publishing Company, Beijing.

[22] Yang, J., Wang, Z. S., Jin, G. (2013): Post-benefit evaluation of land consolidation project implementation based on AHP and FUZZY comprehensive evaluation. Resources and Environment in the Yangtze Basin 22(8): 1036-1042.

[23] Yang, J. Y., Xu, F., Liu, G. C. (2017a): Demarcation method of permanent prime cultivated land based on TOPSIS. - Transactions of the Chinese Society of Agricultural Machinery 48(8): 133-139.

[24] Yang, J. Y., Zhao, L., Xu, F. (2017b): Zoning of high standard prime farmland construction based on arable lands connectivity. - Transactions of the Chinese Society of Agricultural Machinery 48(4): 142-148.

[25] Yang, J. Y., Zhang, X., Xu, F. (2018): Designation method of permanent basic farmland based on TOPSIS and local spatial auto-correlation. - Transactions of the Chinese Society of Agricultural Machinery 49(4): 172-180. 
[26] Zhao, D. L., He, S. S., Lin, S. W. (2017): Selection of high-standard farmland construction priority area based on TOPSIS and hotspot analysis. - Transactions of the Chinese Society of Agricultural Machinery 48(7): 153-158.

[27] Zhao, D. L., Lin, S. W., Yang, J. Y. (2018): Potential of cultivated land quality based on combination of grading factors and matter element analysis. - Transactions of the Chinese Society of Agricultural Machinery 49(4): 181-191.

[28] Zhao, J. R., Zhu, D. L. (2010): Emergy-based analysis of expost benefits of land exploitation and consolidation. - Transactions of the Chinese society of Agricultural Engineering 26(10): 337-344.

[29] Zhao, S. X., Niu, H. P., Zhang, H. B. (2018): Construction and application of obstacle diagnosis model based on ecological niche on well-facilitated farmland. - Transactions of the Chinese Society of Agricultural Machinery 49(1): 194-202.

[30] Zhao, Y. W., Su, N. (2010): Extension Design. - The Science Publishing Company, Beijing. 